\title{
A RELAÇÃO DO ARQUIVISTA COM A GESTÃO DO CONHEÇIMENTO: ANÁLISE EM UMA INSTITUIÇÃO PÚBLICA FEDERAL
}

\section{LA RELACIÓN DEL ARCHIVERO CON LA GESTIÓN DEL CONOCIMIENTO: EL ANÁLISIS EN UNA INSTITUCIÓN PÚBLICA FEDERAL}

\begin{abstract}
Murilo Billig Schäfer - mbsarquivo@yahoo.com.br Mestre pelo Programa de Pós-Graduação Profissional em Patrimônio Cultural da Universidade Federal de Santa Maria (UFSM). Arquivista da

Universidade Federal da Fronteira Sul (UFFS).

Marystela Assis Baratter Sanches - marystela.baratter@gmail.com Doutoranda em Administração pela Universidade Federal do Paraná (UFPR). Professora convidada do Grupo UNINTER.
\end{abstract}

\section{RESUMO}

Introdução: A informação tornou-se elemento imprescindível na tomada de decisão e execução das atividades administrativas das organizações modernas, repercutindo na sua necessidade de gestão.

Objetivo: averiguar a adoção de instrumentos arquivísticos que promovam a gestão de documentos e informações; analisar a percepção do arquivista quanto à gestão do conhecimento na instituição pesquisada; o incentivo e apoio dos gestores no compartilhamento e uso do conhecimento; e, o estudo dos fatores que interferem no desenvolvimento de um programa de gestão do conhecimento.

Metodologia: Levantamento da bibliografia e referencias teóricos e em seguimento, aplicouse um questionário em uma Instituição Pública Federal.

Resultados: O conjunto de fatores verificados serve de parâmetro para demonstrar a situação encontrada nos órgãos governamentais brasileiros e as dificuldades para aplicação da gestão do conhecimento. 
Murilo Billig Schäfer; Marystela Assis Baratter Sanches

A relação do arquivista com a gestão do conhecimento: análise em uma instituição pública federal

Conclusões: apontam-se alternativas para contornar a atual realidade, destacando-se o papel do arquivista, que deve assumir a postura de incentivador no uso da informação e conhecimento produzido pelas organizações.

Palavras-chave: Arquivista. Informação. Gestão do conhecimento. Instituições Públicas Federais.

\section{INTRODUÇÃO}

A gestão nos acervos arquivísticos das organizações, sejam elas públicas ou privadas, torna-se relevante pela necessidade de rapidez na recuperação das informações que servem ao desempenho das tarefas administrativas, resguardam direitos, além de preservar a memória da instituição. Além disso, a tomada de decisão que direciona os objetivos de uma organização, tem como elemento de apoio a informação, esta, encontrada nos documentos.

O presente estudo tem como objetivo demonstrar a relação do profissional arquivista na promoção da gestão do conhecimento em uma Instituição Pública Federal. Para tanto, inicialmente averiguou-se o desenvolvimento da gestão de documentos e gestão da informação na referida instituição, pois são procedimentos que subsidiam a construção e aplicação do conhecimento em ambientes organizacionais.

Destaca-se que os objetivos específicos da pesquisa, pautaram-se em: averiguar a adoção de instrumentos arquivísticos que promovam a gestão de documentos e informações; analisar a percepção do arquivista quanto à gestão do conhecimento na instituição pesquisada; o incentivo e apoio dos gestores no compartilhamento e uso do conhecimento; e, o estudo dos fatores que interferem no desenvolvimento de um programa de gestão do conhecimento.

A análise e compreensão das características que influenciam a gestão do conhecimento tornam-se fundamentais para que as organizações encontrem soluções plausíveis no gerenciamento de seus ativos intelectuais. Além disso, o desenvolvimento do estudo em uma Instituição Pública Federal, repercute em respostas que podem ser aplicadas em outros contextos institucionais, destacandose os de caráter público. 


\section{REVISÃO DA LITERATURA}

\subsection{O Arquivista e a Gestão do Conhecimento}

A arquivística, por meio de suas tarefas (classificação, avaliação, descrição, etc.) orienta 0 desenvolvimento da organização, recuperação e acesso aos documentos e informações. Segundo a Lei 8.159, de 08 de janeiro de 1991, que dispõe sobre a política nacional de arquivos públicos e privados, considera a gestão de documentos como o "conjunto de procedimentos e operações técnicas referentes à sua produção, tramitação, uso, avaliação e arquivamento" dos documentos (BRASIL, 1991).

A arquivística tem o auxílio de diversas áreas do conhecimento, citando-se, por exemplo, a informática, a história, a comunicação, a administração, entre outras, para consecução de suas atividades. Dando destaque especial para a administração, esta se relaciona com a arquivística, pois é a principal responsável pela produção dos documentos com caráter arquivístico. Percebe-se essa relação ao longo do tempo nas palavras de Rousseau e Couture (1998), que definem que os arquivos constituem uma fonte de informação única a respeito das pessoas e das organizações, estando na base da administração dos estados e das organizações, tal como as malhas da cadeia que permitem a transmissão e o testemunho de seus usos e costumes.

$\mathrm{Na}$ arquivística, os arquivos correntes são aqueles que ficam depositados, temporariamente, os documentos produzidos pelas administrações, que são utilizados para a realização das atividades rotineiras e cotidianas. Dessa forma, estes documentos devem permanecer o mais perto possível de quem os utiliza, possibilitando a rápida recuperação das informações, independentemente do suporte em que se encontram.

Dada a importância dos arquivos correntes, torna-se primordial não apenas a atuação do arquivista - através da gestão de documentos -, mas também a percepção do gestor da organização para esta questão. Rosa (2007, p. 1) afirma que "sempre que se busca um documento é por necessidade de se obterem informações, e em virtude disso, os arquivos deixam de ser apenas depósitos e transformaram-se em centro ativos de informações a serviço da administração." E 
Murilo Billig Schäfer; Marystela Assis Baratter Sanches

A relação do arquivista com a gestão do conhecimento: análise em uma instituição pública federal

com essa percepção de centro ativo de informações que os gestores devem compreender o arquivo, possibilitando que a gestão de documentos e informações seja efetivada na organização. Somente dessa forma, as informações estratégicas poderão ser adequadamente recuperadas para auxiliar na execução das tarefas administrativas.

Passando da conceituação da gestão de documentos para a gestão da informação, pode-se definir esta última como o conjunto de tarefas e processos com a finalidade de criar, utilizar, resguardar e recuperar a informação que uma empresa detém. Estando a informação à disposição, as tarefas administrativas podem ser desempenhadas com melhor qualidade, rapidez e segurança.

Braga (1996) caracteriza a gestão da informação como uma forma de gestão, que tem como objetivo apoiar a política global da empresa, na medida em que torna mais eficiente o conhecimento e a articulação entre os vários subsistemas que a constituem. Além disso, apoia os gestores na tomada de decisão, torna mais eficaz o conhecimento do meio envolvente e estimulando a evolução da estrutura organizacional.

As organizações estão percebendo, e cada vez mais, a importância da informação para alcançar seus objetivos. Pode-se visualizar tal questão na seguinte citação de Ferreira (2003, p. 48) onde ele expõe que "o mercado reconhece a necessidade e o valor da informação, a necessidade de habilidade e competências para se trabalhar com a informação, identificando as funções para desenvolver essa prática".

Ao mesmo tempo em que as organizações dão valor à informação, os profissionais que trabalham com a gestão desse elemento ganham importância. No caso dos arquivistas, estes são imprescindíveis para a promoção da gestão de documentos, o que repercute no desenvolvimento da gestão da informação, e consequentemente, esta sustenta a gestão do conhecimento.

Toda a produção informacional de uma organização é registrada em documentos (papel), publicações, banco de dados, mídias e demais suportes. $\mathrm{O}$ arquivista, responsável pela organização, salvaguarda, recuperação e acesso à informação constante nesses acervos, torna-se indispensável no processo de gestão da informação. Ribeiro (2004, p. 9) coloca que "a revolução tecnológica e digital tornou inevitável a mudança de paradigma e está a arrastar definitivamente a 
Murilo Billig Schäfer; Marystela Assis Baratter Sanches

A relação do arquivista com a gestão do conhecimento: análise em uma instituição pública federal

Arquivística para o campo da Ciência da Informação, já que o objeto de estudo e de trabalho é um só: a informação”. O autor acrescenta que

[...] o tradicional arquivista, conservador de testemunhos ou guardador de documentos ao serviço da investigação, particularmente a histórica, terá de se assumir como um gestor e estruturador da informação, gerada, usada e acumulada como memória em qualquer contexto orgânico e funcional (RIBEIR, 2004, p. 9).

De modo geral, Cardoso e Valentim (2008, p. 2) explicam que,

A informação, a cada dia, torna-se essencial à vida de toda a sociedade. Os profissionais que atuam, diretamente, com a informação passam a ter um papel de destaque na denominada Sociedade da Informação, contudo esse destaque é proporcional à responsabilidade que o profissional da informação passa a ter.

Cardoso e Valentim (2008) enfatizam o caso singular do profissional arquivista, que necessita apropriar-se de competências e habilidades específicas, bem como deve aplicá-las no ambiente ao qual irá atuar, ou seja, o profissional necessita ter conhecimento dos recursos que norteiam a gestão da informação para desenvolvimento do seu trabalho, pois se encontra em um ambiente de constante mudança.

Avançando para o tema gestão do conhecimento, este se caracteriza pelo uso eficaz e direcionado da informação produzida e/ou agregada pela empresa. Baseiase no conhecimento existente nos diversos setores da empresa, nos seus colaboradores, nos fluxos e processos de trabalho diários, visando o aperfeiçoamento e desenvolvimento da organização como um todo.

Demonstra-se que o conhecimento está presente e manifesta-se nos diversos níveis, setores, pessoas e processos que envolvem uma organização. Conseguir gerenciar esse conhecimento que na maioria das vezes não está explícito, constituindo-se em um grande desafio.

Os autores Bukowitz e Williams (2002) descrevem a gestão do conhecimento como o processo pelo qual a organização gera riqueza a partir do seu conhecimento ou capital intelectual. O capital intelectual ou conhecimento é qualquer coisa valorizada pela organização que esteja contido nas pessoas, ou seja, deriva de 
Murilo Billig Schäfer; Marystela Assis Baratter Sanches

A relação do arquivista com a gestão do conhecimento: análise em uma instituição pública federal

processos, de sistemas e de cultura organizacional - conhecimento e habilidades individuais, normas e valores, bases de dados, metodologias, software, Know-How, licenças, marcas e segredos comerciais.

Aprofundando-se nas características que envolvem o conhecimento, principalmente relativo às organizações, pode-se classificá-lo em explícito e tácito. Os autores Nonaka e Takeuchi (1997 apud SILVA, 2004, p. 145) definem que o formato tácito é subjetivo, percepção e experiência, difícil de ser formalizado, transferido ou explicado, enquanto que o formato explícito é relativamente fácil de codificar, transferir e reutilizar, formalizado em gráficos, tabelas, figuras, esquemas, etc., facilmente organizados em bases de dados, tanto em formato papel quanto em formato eletrônico. Destaca-se que o conhecimento explícito é um conhecimento "visível", pois está registrado em documentos como desenhos, correspondências, periódicos, relatórios, entre tantos outros que se configuram na sua maioria como documentos arquivísticos. Enquanto isso, o conhecimento tácito é abstrato, relacionado à experiência do indivíduo, sua sabedoria, sua cultura, e afins, que não se encontra visível em registros e documentos.

Analisando-se as características do conhecimento, podemos refletir para a importância que um setor gestor de documentos - o Arquivo - faz junto a uma organização e seu processo de administrar. O setor de "Arquivo" torna-se fundamental na implantação da gestão do conhecimento, pois nele são armazenados, gerenciados e disponibilizados os documentos que contêm informações estratégicas produzidas pela organização, não apenas no presente, mas também decisões passadas que construíram a trajetória da instituição.

Rosa (2007) comenta que a segurança oportunizada pela documentação devidamente registrada em arquivos revela a história de uma instituição, servindo como fonte de conhecimento para a tomada de decisão pelos administradores. Isso ocorre desde que a informação esteja devidamente organizada em arquivos.

Considerando a utilização do conhecimento tácito e explícito na gestão do conhecimento, destaca-se 0 arquivo da organização como gerenciador das informações explícitas, contidas em documentos, publicações e demais suportes arquivísticos. Barreto (2004) cita em seu artigo o pensamento de Thomas Davenport e Laurence Prusak, que defendem que uma instituição ao dispor de um bom arquivo, 
Murilo Billig Schäfer; Marystela Assis Baratter Sanches

A relação do arquivista com a gestão do conhecimento: análise em uma instituição pública federal

um sistema de banco de dados textual, ou mesmo programas eficazes de educação, já estará fazendo algo que pode estar sendo direcionado à gestão do conhecimento.

Fica claro que as funções do setor de arquivo de uma organização estão intimamente ligadas à gestão do conhecimento. O processo de gestão de documentos, informação e consequentemente do conhecimento, mantêm uma relação direta, sendo a primeira a base para as seguintes.

Um importante fator para a efetivação da gestão do conhecimento é a conscientização dos colaboradores da instituição. São eles que trabalham diariamente com as informações que a empresa utiliza para consecução de suas atividades, e necessitam participar desse processo para que a gestão documental e informacional seja desenvolvida constantemente. Isso possibilita não apenas a recuperação eficaz das informações, mas a garantia de que apenas as informações relevantes serão preservadas, sendo estas as responsáveis pelo desenvolvimento das organizações.

O excesso de informações é, por vezes, considerado um fator irrelevante, mas Ferreira (2003, p. 43) destaca que:

Muito mais importante é a qualidade da informação [...] a informação agrega valor ao negócio quando da sua análise chega-se a novas maneiras de fazer negócio, a novos serviços a novos produtos. [...] Há muita discussão sobre as atribuições e responsabilidades relacionadas com os dados, as informações e o conhecimento da empresa, o que justifica ter como objeto de estudo o profissional da informação voltado para a prática da gestão do conhecimento.

Pela citação de Ferreira (2003), reitera-se a importância do envolvimento dos arquivistas e profissionais da informação na aplicação da Gestão do Conhecimento. Tanto a alta administração, que define as estratégias organizacionais, como os colaboradores que utilizam a informação para consecução de suas tarefas profissionais, devem compreender a relevância do processo de transformação da informação em conhecimento e o que isso proporciona em benefícios para a organização em que atuam.

Barreto (2004, p. 2) afirma que "as organizações precisam de pessoas para extrair o conhecimento daqueles que o têm, colocar esse conhecimento numa forma estruturada e mantê-lo ou aprimorá-lo, agregando-lhe valor ao longo do tempo". Enquanto isso, Rosa (2007) destaca que as empresas promoverão a criação, o 

federal

acesso, a transferência, o uso efetivo do conhecimento em benefício dos negócios para que elas encontrem melhores maneiras de mobilizar e alavancar 0 conhecimento individual, e para que este possa se tornar parte integrante do conhecimento organizacional.

A gestão do conhecimento deve ser parte do trabalho de cada profissional da empresa, pois o conhecimento torna-se cada vez mais em um capital que serve para a competitividade e estratégias empresariais.

Para finalizar, pode-se considerar a opinião de Ferreira (2003) reiterando a relação do profissional da informação com a gestão do conhecimento. Considera que o papel do profissional da informação é o de assistir, intermediar e apoiar outras pessoas na busca de informações, por meio da gestão do conhecimento. A evolução de conceitos, tecnologia, formatos e suportes, amplia, evolui e diversifica a essência desse trabalho, demandando modificações às exigências de atuação, formação e capacitação desse profissional.

\section{METODOLOGIA}

Este artigo é resultante de uma pesquisa realizada no segundo semestre de 2011, relatando as características sobre o tema Gestão do Conhecimento aplicado em uma Instituição Pública Federal e sua relação com as atividades do profissional arquivista.

Os procedimentos técnicos utilizados basearam-se primeiramente no levantamento da bibliografia e referencias teóricos sobre os temas gestão de documentos, informação e conhecimento, destacando-se a consulta predominante em artigos de cunho acadêmico e científico. Em seguimento, aplicou-se um questionário em uma Instituição Pública Federal (por questões de sigilo e imparcialidade do estudo, teve seu nome preservado), situada no estado de Santa Catarina, Brasil. A seleção da instituição baseou-se no critério de apresentar em seu quadro de colaboradores/servidores arquivistas (com formação acadêmica em curso superior de Arquivologia), que atuassem na gestão de documentos e informações.

Os dados coletados na referida instituição foram analisados e transpostos no capítulo "A percepção da gestão do conhecimento em uma Instituição Pública 
Federal", onde a confrontação de ideias serviu para a obtenção de subsídios utilizados na construção das conclusões do estudo.

\section{A PERCEPÇÃO DA GESTÃO DO CONHECIMENTO EM UMA INSTITUIÇÃO PÚBLICA FEDERAL}

De acordo com os dados coletados na Instituição Pública Federal integrante do estudo, apresenta-se uma discussão sobre os elementos que interferem na promoção da gestão do conhecimento, abordando-se aspectos referentes à gestão de documentos e informações, formação dos profissionais arquivistas e incentivos para o desenvolvimento de programas de gestão do conhecimento.

O primeiro elemento abordado no questionário referiu-se a respeito da existência da gestão de documentos na Instituição, baseado-se na existência e aplicação de instrumentos como Plano de Classificação, Tabela de Temporalidade de Documentos, entre outros. O cenário encontrado remete ao desenvolvimento parcial da gestão de documentos, pois somente recentemente a Instituição contou oficialmente com arquivistas no seu quadro de servidores, para suprir a necessidade de implantação de procedimentos que visam gerenciar a produção documental.

Anteriormente à contratação dos arquivistas, a gestão documental ocorria apenas em determinados setores, não havendo uma política para toda a instituição. Atualmente, utiliza-se uma Tabela de Temporalidade de Documentos que apresenta os assuntos resultantes das atividades da Instituição, servindo como modelo para a classificação dos documentos. Há também uma Comissão Permanente de Avaliação de Documentos, responsável pela orientação, revisão e adaptação da Tabela de Temporalidade de Documentos.

Denota-se que as iniciativas de efetivação da gestão de documentos estão presentes na Instituição, constituindo-se como um fator favorável ao desenvolvimento e aplicação da Gestão da Informação e do Conhecimento. Por se tratar de um processo complexo e de longo prazo, a gestão do conhecimento necessita de atividades auxiliares para ser efetivada, sendo a gestão de documentos uma delas.

Rosa (2007) estabelece uma relação muito clara entre gestão de documentos com a gestão do conhecimento, ao afirmar que as organizações que incorporam a 
gestão do conhecimento, e junto a essa, um programa de gestão documental, o conhecimento produzido e documentado estará acessível e usado regularmente pelos colaboradores e equipes durante os projetos e/ou condução dos processos regulares de trabalho. A autora ainda esclarece que gestão do conhecimento e da informação documental estão intrinsecamente ligadas, visto que, se decisões são pautadas com base em documentos, estes devem estar no lugar certo e na hora certa.

Diante disso, considera-se a gestão de documentos como precursor para a implantação da gestão do conhecimento, e isto já ocorre na Instituição pesquisada.

O segundo questionamento refere-se à aplicação da gestão da informação, através de instrumentos como taxonomias, tesauros, índices, entre outros. Afirmouse que na Instituição, os "tesauros" foram definidos para aplicação no protocolo eletrônico de processos administrativos e correspondências, permitindo o controle (parcial) na utilização de termos e vocabulários para recuperação da informação. Além disso, existem índices (como por exemplo, os termos de transferência de documentos) que permitem a localização de informações que compõem o acervo documental da Instituição.

Do mesmo modo que para a gestão de documentos, há aplicação de instrumentos para a gestão da informação (tesauros, índices, taxonomias, etc.), servindo como subsidiários da gestão do conhecimento. Angeloni (1999) explica que setores e organizações vem fazendo o uso intensivo da informação ou do conhecimento como subsídio à gerencia de seus negócios. A disponibilidade de informações seguras e confiáveis como base para o processo decisório e objetivos estratégicos da empresa torna-se fundamental. No entanto, para que a gestão do conhecimento seja implementada na organização, deve ser considerada a necessidade de um gerenciamento de informações.

Quando se trata do entendimento por parte dos arquivistas sobre o que é, e o que envolve a gestão do conhecimento, há o entendimento conceitual sobre o tema, mas na prática ainda não está claro como efetivá-lo. Ou seja, os profissionais conhecem teoricamente a abrangência da gestão do conhecimento, mas não ao nível de garantir sua aplicação. Diante disso, cabe supor que a gestão do conhecimento pode até estar sendo parcialmente desenvolvida, mas sem a consciência dos profissionais envolvidos neste processo, repercutindo em resultados 
pouco satisfatórios.

Aprofundando-se no aspecto da aplicação da gestão do conhecimento, o setor responsável pela gestão documental e da informação desenvolve ações específicas de sua área, constituindo-se apenas como uma parte do processo, sem poder promover a gestão do conhecimento por si só em toda a Instituição. Acrescenta-se que segundo as informações coletadas na Instituição, os responsáveis pelo desenvolvimento de instrumentos como intranets, mapas do conhecimento, etc. (instrumentos da gestão do conhecimento), devam ser os setores responsáveis pela administração geral da Instituição. Os índices elaborados e utilizados pelo setor da informação (citados anteriormente), podem auxiliar na promoção da informação e principalmente do conhecimento, mas só terão efeitos se for levado em consideração quem os utiliza e o modo como o fazem.

Desse contexto, podemos destacar dois pontos fundamentais. O primeiro são as ações isoladas de setores que não possibilitam a promoção do conhecimento para toda a instituição. Barreto (2004, p. 2) esclarece essa questão ao afirmar que "grande parte da energia dos Programas de Gestão do Conhecimento está dirigida a encontrar fórmulas e unidade independente, quando na realidade o Conhecimento faz parte de toda a Instituição". Em segundo, destaca-se a importância de identificar quem utiliza o conhecimento e para que finalidade, pois a gestão do conhecimento baseia-se no capital intelectual contido nas pessoas, sua cultura organizacional, habilidades, valores pessoais, etc. Coelho (2004, p. 98) acrescenta que "gestão do conhecimento também é um novo modelo de gerenciamento das organizações, focado na aprendizagem contínua, na estratégia da inovação e na geração do conhecimento."

Baseado nessas afirmações destaca-se a dificuldade na efetivação da gestão do conhecimento, cujo foco não pode se restringir a setores ou áreas específicas, mas sim, levar em consideração todo o ambiente organizacional.

Para se compreender a abrangência que a gestão do conhecimento requer dos profissionais envolvidos, questionou-se aos arquivistas acerca da abordagem dos temas gestão da informação e gestão do conhecimento durante a formação acadêmica. De acordo com a resposta obtida, o tema gestão da informação é frequentemente abordado, enquanto a gestão do conhecimento (por ser um assunto mais recente) não ganha tanto destaque. Grande parte do aprendizado adquirido 
sobre gestão do conhecimento é resultante de interesse pessoal, através de pesquisas e leituras, sendo que exige dos profissionais envolvidos uma formação específica e contínua, pois conceitos, tecnologias e práticas dessa área estão em permanente mudança.

Em relação à existência de programas, incentivos ou eventos que promovam a gestão do conhecimento na Instituição, relatou-se que quando ocorrem eventos que tratam sobre os temas de gestão da informação e conhecimento, e seja de interesse dos servidores em consonância aos objetivos da Instituição, os profissionais podem solicitar "liberação" de suas atividades diárias para participação. Esporadicamente, a própria Instituição promove eventos sobre esse tema.

Embora a Instituição seja flexível referente à participação dos servidores em eventos que tratem de temas como gestão da informação e conhecimento, ao mesmo tempo, não os incentiva permanentemente à conhecerem e aplicarem tais temas. Barreto (2004) afirma que apesar do jargão corporativo de que o conhecimento do funcionário é um recurso valioso, a maioria das empresas não empreende esforços organizados junto a seu pessoal para cultivar atividades orientadas ao conhecimento corporativo, de forma a preservá-lo.

Coelho (2004) comenta a falta da cultura para a aprendizagem na administração pública, onde não há ambientes voltados para a aprendizagem organizacional e/ou para a inovação e, com raras exceções, também não incentivam a educação continuada de seus servidores. Percebe-se que as organizações públicas enfrentam inúmeras resistências às mudanças e à efetiva implementação dos modelos e das ferramentas de gestão do conhecimento.

Além disso, observa-se que há obstáculos mais complexos do que a simples falta de abordagem do tema gestão do conhecimento na formação dos arquivistas. A aprendizagem contínua e ambientes favoráveis ao desenvolvimento das práticas da gestão do conhecimento precisam ser consideradas como elementos primordiais na produção, compartilhamento e uso da informação e conhecimento.

Quanto ao comprometimento da administração superior para o desenvolvimento e aplicação de programas de compartilhamento de informações e conhecimento, o cenário institucional demonstra a realização de ações isoladas neste processo. Não há uma política institucional voltada para o tema, sendo que as iniciativas de compartilhamento da informação ocorrem de forma segmentada, 
repercutindo em resultados aquém do esperado para a implementação da gestão do conhecimento. Rosa (2007, p. 13) destaca a informação como parte integrante da gestão do conhecimento. "A gestão do conhecimento surgiu como uma ferramenta gerencial para administrar a informação e agregar-lhe valor. Dessa forma, as empresas promoverão a criação, o acesso, a transferência, o uso efetivo do conhecimento em beneficio dos negócios".

Complementando acerca do aspecto da formação dos arquivistas frente ao tema da gestão do conhecimento, investigou-se em relação ao incentivo à qualificação e aperfeiçoamento dos arquivistas na instituição. Sem considerar especificamente a área da gestão da informação e conhecimento, a Instituição mantém uma política de incentivo à qualificação profissional para seus servidores, especialmente para a realização de cursos em pós-graduação, nível de mestrado. Esporadicamente, a Instituição oferece cursos a respeito do tema gestão do conhecimento, mas cita-se como um fator prejudicial na organização destes, o limitado número de vagas, interferindo em uma das principais premissas de um programa de gestão de conhecimento que é a compreensão do funcionamento da gestão por todos os setores e colaboradores/servidores de uma instituição.

Neste sentido, Barreto (2004) esclarece que as melhores empresas do futuro serão aquelas nas quais todos poderão criar e usar de forma compartilhada o conhecimento. Ainda há grande número de empresas que entende que 0 conhecimento é obrigação de um único grupo. É necessário um longo tempo para mudar essa cultura, cabendo às lideranças empresariais desenvolver ações para apregoar a crença de que trabalhar o conhecimento é dever de todo mundo.

O último aspecto questionado referiu-se aos elementos necessários para implantar e/ou desenvolver a gestão da informação e conhecimento na Instituição. Foram destacados seis pontos considerados fundamentais:

$1^{\circ}$ Consciência da necessidade da gestão da informação e conhecimento por parte de todos na Instituição, abrangendo todos os níveis, sendo que a iniciativa deve partir dos órgãos superiores;

$2^{\circ}$ Difusão de todos os conceitos antes do processo de implantação, para que os integrantes assumam uma postura receptiva frente à gestão da informação e conhecimento; 
$3^{\circ}$ Avaliação e investimento em todos os recursos necessários (humanos, tecnológicos, financeiros, etc.) para que a gestão seja efetivada;

$4^{\circ}$ Além de haver amparo torna-se necessário o acompanhamento do processo, para que se mantenha o trabalho e a motivação dos envolvidos. Como exemplos, pode-se citar a divulgação periódica dos resultados que foram alcançados, o reforço na conscientização e importância do processo, principalmente na fase de implantação;

$5^{\circ}$ Analise das práticas efetivadas em outras instituições, promovendo a troca de experiências e ideias;

$6^{\circ}$ Correção das tarefas que não surtiram efeitos desejados, e difusão dos acertos obtidos.

Os pontos destacados pressupõem um contexto que propõe a criação e efetivação de programas de gestão do conhecimento partindo da alta administração, conscientizando todos os envolvidos, avaliando a necessidade de investimentos humanos, tecnológicos e financeiros, e mantendo um feedback de todo o processo.

Fresneda e Gonçalves (2008, p. 5) em seus estudos aplicados à Administração Pública Federal, comenta sobre a necessidade de apoio da alta administração para a aplicação da Gestão do Conhecimento.

As ações da GC nas organizações da APF são fragmentadas, de efeito limitado ao escopo das unidades organizacionais e não alinhados as estratégias e orientações gerais corporativas. [...] para se elaborar um plano corporativo de GC é necessário o apoio decidido e comprometido da alta administração das organizações da APF.

Pode-se considerar o apoio da alta administração como elemento central no sucesso de um programa de gestão do conhecimento, evitando-se assim, ações compartimentadas por setores ou áreas que não alcançam o objetivo de efetivar o uso da informação e conhecimento nas atividades de uma instituição. Coelho (2004, p. 106) ao tratar desse assunto, propõe o desenvolvimento de um modelo de gestão do conhecimento baseado em cinco sistemas permanentes de gerenciamento: "a) do planejamento estratégico; b) da padronização de procedimentos; c) do capital intelectual; d) do ambiente de inovação; e, e) da aprendizagem contínua."

A aprendizagem contínua dos colaboradores/servidores envolvidos 
caracteriza-se como um fator de extrema relevância em programas de gestão da informação e conhecimento. Ele permite aos colaboradores identificarem suas ações em meio ao processo, tornando-os elementos conscientes, participativos e promotores do conhecimento. Coelho (2004) comenta que as organizações públicas devem desenvolver estratégias justas, inovadoras e democráticas de forma a que os colaboradores possam estar permanente e continuamente aperfeiçoando suas habilidades e seus conhecimentos.

Ao se finalizar a discussão, ressalta-se que o cenário relatado neste artigo retrata a realidade (com possíveis exceções) da situação que se encontram os programas de gestão de documentos, informação e conhecimento nas Instituições Públicas Federais no Brasil. Observa-se que são vários os desafios existentes, mas para que ocorra a efetivação desses programas é necessário estudar suas características e repercussões, a fim de que alcancem aos objetivos a que se propõem.

\section{CONSIDERAÇÕES FINAIS}

Com base nas considerações apresentadas no desenvolvimento do estudo, destaca-se a relevância do arquivista frente à gestão do conhecimento nas organizações, em especial, nas de caráter público. Serra Júnior (2006 p. 13) destaca que "o conhecimento arquivístico, associado com os demais saberes das ciências da informação, é fundamental para o sucesso de projetos de gestão do conhecimento".

Embora o foco da pesquisa seja o arquivista, os fatores identificados como limitadores da aplicação da gestão do conhecimento na Instituição, ultrapassam os limites das atividades desempenhadas por este profissional. Pode-se citar o apoio limitado da alta administração no desenvolvimento de programas de gestão - de documentos, informações e conhecimento -, falta de conscientização dos colaboradores sobre a importância e a repercussão que o conhecimento é capaz de propiciar para o desempenho de suas atividades, cultura organizacional que não incentiva mudanças e inovação, entre outros.

No caso específico das Instituições Públicas Federais, Fresneda e Gonçalves (2008) comentam que a finalidade de uma política de Gestão do Conhecimento, é melhorar a eficiência, eficácia, efetividade e qualidade da formulação e 
Murilo Billig Schäfer; Marystela Assis Baratter Sanches

A relação do arquivista com a gestão do conhecimento: análise em uma instituição pública federal

implementação de políticas e serviços públicos prestados ao cidadão e à sociedade brasileira. Além disso, promove a transparência na gestão pública, criação de cultura voltada para a importância e utilidade da informação e do conhecimento.

Embora sejam vários os benefícios promovidos pela gestão do conhecimento, sua adoção nas instituições públicas é rara, e este cenário somente poderá ser modificado ao longo do tempo. Para tanto, é necessário alterar a cultura habitual das instituições - pois estas estão em processo inicial de reconhecimento do valor de suas informações -, de forma a promover o conhecimento como elemento fundamental para o desempenho de suas atividades.

$\mathrm{O}$ arquivista necessita assumir no contexto das organizações, especialmente as públicas, a função de incentivador das práticas relacionadas ao uso da informação e conhecimento, adotando uma postura pró-ativa no desempenho de suas funções como profissional da informação. Serra Júnior (2006) ressalta que este profissional deve repensar os aspectos tradicionais de suas atividades, como: o foco nos acervos documentais, os registros físicos como seu principal objeto de trabalho e a gestão de documentos como sua principal responsabilidade administrativa e de prestação de serviços. Devem pensar nas informações organizacionais, como fontes de conhecimento, participando ativamente no esforço de aprendizado organizacional.

Por fim, baseado nas ideias citadas pelo autor acima, destaca-se a aprendizagem organizacional como alternativa imprescindível na constituição da gestão do conhecimento nas organizações públicas e privadas. Tanto a instituição como seus colaboradores, necessitam aprender o que envolve a gestão do conhecimento, sua abrangência, objetivos que pretende alcançar, e principalmente, as funções que caberão a cada um dos envolvidos nesse processo.

\section{REFERÊNCIAS}

ANGELONI, Maria Terezinha et al. Gestão estratégica da informação e o processo decisório: uma preparação para a gestão do conhecimento. In: ENEGEP, 19., 1999, Rio de Janeiro. Anais... Rio de Janeiro, 1999. 
Murilo Billig Schäfer; Marystela Assis Baratter Sanches

A relação do arquivista com a gestão do conhecimento: análise em uma instituição pública federal

BARRETO, Auta Rojas. Implantação de gestão do conhecimento a partir dos repositórios de conhecimento explícito. In: CONGRESSO BAD, 8., 2004, Estoril.

Anais... Estoril, 2004. Disponível em: <http://www.apbad.pt/Edicoes/EdicoesCongresso8.htm>. Acesso em: 22 out. 2011.

BRAGA, Ascenção. A gestão da informação. 1996. Disponível em: <http://www.ipv.pt/millenium/19_arq1.htm>. Acesso em: 15 out. 2011.

BRASIL. Lei n. 8.159, de 8 de janeiro de 1991. Dispõe sobre a política nacional de arquivos públicos e privados e dá outras providências. Disponível em: <http://www.planalto.gov.br/ccivil_03/leis/L8159htm>. Acesso em: 13 out. 2011.

BUKOWITZ, Wendi R.; WILLIAMS, Ruth L. Manual de gestão do conhecimento. Tradução de Carlos Alberto Silveira Netto Soares. Porto Alegre: Bookman, 2002.

CARDOSO, Débora Regina; VALENTIM, Marta Lígia Pomim. Perfil do profissional arquivista para atuar com a gestão documental em ambientes empresariais. In: ENCONTRO NACIONAL DE ESTUDANTES DE ARQUIVOLOGIA, 12., 2008, Salvador. Anais... Salvador, 2008. Disponível em: $<$ http://www.enearq2008.ufba.br/wpcontent/uploads/2008/09/13debora_regina_cardo so.pdf>. Acesso em: 25 set. 2011.

COELHO, Espartaco Madureira. Gestão do conhecimento como sistema de gestão para o setor público. Revista do Serviço Público, Brasília, v. 55, n. 1, p. 89-115, 2004.

FERREIRA, Danielle Tiago. Profissional da informação: perfil de habilidades demandadas pelo mercado de trabalho. Ciência da Informação, Brasília, v. 32, n.1, p. 42-49, jan./abr. 2003. Disponível em: <http://www.scielo.br/pdf/ci/v32n1/15972.pdf>. Acesso em: 25 set. 2011.

FRESNEDA, Paulo Sérgio Vilches; GONÇALVES, Sonia Maria Goulart. Diretrizes orientadoras para a implantação da Gestão do conhecimento na administração pública federal. In: CONGRESSO IBERO-AMERICANO DE GESTÃO DO CONHECIMENTO E INTELIGÊNCIA COMPETITIVA, 2., 2008, Brasília. Anais... Brasília, 2008. Disponível em: <www.consad.org.br/sites/1500/1504/00000806.doc>. Acesso em: 17 out. 2011.

RIBEIRO, Fernanda. O perfil profissional do arquivista na sociedade da informação. In: JORNADAS LUSO-CABOVERDIANAS EM CIÊNCIAS SOCIAIS - PORTUGAL E CABO VERDE, 4., 2004, Porto. Anais... Porto, 2004. Disponível em:

http://ler.letras.up.pt/uploads/ficheiros/artigo8871.PDF>. Acesso em: 25 jun. 2011.

ROSA, Vera Lucia da. A importância de um arquivo organizado para a gestão do conhecimento na empresa. In: CONGRESSO MERCOSUL, 2007, Tubarão. Anais... Tubarão, 2007.

ROUSSEAU, Jean-Yves; COUTURE, Carol. Os fundamentos da disciplina arquivística. Lisboa: Publicações Dom Quixote, 1998. 
Murilo Billig Schäfer; Marystela Assis Baratter Sanches

A relação do arquivista com a gestão do conhecimento: análise em uma instituição pública federal

SERRA JÚNIOR, Lamberto Ricarte. O papel do arquivista na gestão do conhecimento. 2006. Disponível em:

<http://www.cid.unb.br/publico/setores/000/84/materiais/2007/1/530/0\%20papel\%20d ०\%20arquivista\%20na\%20gest\%C3\%A30\%20do\%20conhecimento.pdf >. Acesso em: 12 set. 2011.

SILVA, Sergio Luis. Gestão do conhecimento: uma revisão crítica orientada pela abordagem da criação do conhecimento. Ciência da Informação, Brasília, v. 33, n. 2, p. 143-151, maio/ago. 2004. Disponível em: <http://www.scielo.br/pdf/ci/v33n2/a15v33n2.pdf>. Acesso em: 12 set. 2011.

\section{Title}

The relation the archivist of knowledge management: analysis in a public institution federal

\section{Abstract}

Introduction: the information has become an indispensable element in decision making and execution of administrative activities of modern organizations, reflecting their need for management.

Objective: to investigate the adoption of archival instruments to promote the management of documents and information, to analyze the perception related to the archivist regarding the management of knowledge in the research institution, the encouragement and support of managers in the sharing and use of knowledge as well as to study the factors that affect the development of a knowledge management program.

Methodology: Literature review and a questionnaire management on a Federal Public Institution.

Results: the set of factors checked parameter serves to demonstrate the situation found in the Brazilian government and the subject of knowledge management and the difficulties in it's development.

Conclusions: it was pointed out alternatives to help the current situation, highlighting the role of the archivist who must assume the posture of encouraging the use of information and knowledge produced by organizations.

Keywords: Archivist. Information. Knowledge management. Federal Public Institutions.

\section{Titulo}

La relación del archivero con la gestión del conocimiento: el análisis en una institución pública federal

\section{Resumen}


Murilo Billig Schäfer; Marystela Assis Baratter Sanches

A relação do arquivista com a gestão do conhecimento: análise em uma instituição pública federal

Introducción: La información se ha convertido en un elemento indispensable en la toma de decisiones y la ejecución de las actividades administrativas en las organizaciones modernas, lo que refleja la necesidad de una gestión.

Objetivo: Investigar la adopción de instrumentos archivísticos para promover la gestión de documentos y la información, para analizar la percepción de archivista en relación con gestión del conocimiento en la institución de investigación, el fomento y el apoyo de los gerentes en el intercambio y uso de conocimientos, y estudio de los factores que interfieren con el desarrollo de un programa de gestión del conocimiento.

Metodología: Búsqueda de bibliografía y referencias y en seguimiento, se aplicó un cuestionario en una Institución Pública Federal.

Resultados: El conjunto de parámetros factores comprobar sirve para demostrar la situación encontrada en el gobierno de Brasil y las dificultades en la implementación de la gestión del conocimiento. Dado lo anterior, se señaló manera de superar esta situación, destacando el papel del archivero, quien asumirá el cargo de fomentar el uso de la información y el conocimiento producido por las organizaciones.

Conclusiones: Señaló alternativas para eludir la realidad actual, destacando el papel del archivero quien debe asumir una postura de fomentar el uso de la información y el conocimiento producido por las organizaciones.

Palabras clave: Archivero; Información; Gestión del conocimiento; Institución Pública Federal.

Recebido em: 10.04 .2012

Aceito em: 30.09 .2013 